\title{
Trypanosoma cruzi: tripomastigotes en líquido pleural de un paciente con SIDA
}

\author{
Claudia Menghi R., Claudia Gatta de N., Anabela Angeleri G., Adriana Rocher C. y Luis Palaoro I.
}

\section{Trypanosoma cruzi: trypomastigote forms in pleural fluid of a patient with AIDS}

The presence of numerous trypomastigote forms of Trypanosoma cruzi in the pleural fluid of a patient with AIDS from Santiago del Estero, Argentina, was detected. Chagas disease is endemic in some countries of Latin America. To our knowledge, the finding of trypomastigote forms of $T$. cruzi in the pleural fluid has not yet been described in the literature.

Palabras clave: Trypanosoma cruzi, líquido pleural, SIDA, Argentina.

\author{
Universidad de Buenos Aires. \\ Argentina. \\ Facultad de Farmacia y Bioquímica \\ Hospital de Clínicas \\ Departamento de Bioquímica Clínica \\ Laboratorio de Parasitología (CMR, \\ CGdeN). \\ Laboratorio de Citología (AAG, \\ ARC, LPI). \\ Recibido: 9 de enero de 2011 \\ Aceptado: 2 de agosto de 2011

\section{Claudia Menghi R.} \\ Correspondencia a: \\ cmenghi@fibertel.com.ar
}

\section{Introducción}

L a enfermedad de Chagas es endémica en algunos países de Latinoamérica. El primer caso de asociación de enfermedad de Chagas y SIDA fue descrito por Del Castillo y cols, en un paciente hemofílico con glioma cerebral, en el año $1990^{1}$. En 1994 Rocha y cols, realizaron una revisión de 23 pacientes procedentes de Brasil, Chile y Argentina, con infección por VIH y enfermedad de Chagas, que presentaban lesiones multifocales graves en el sistema nervioso central (SNC), meningoencefalitis difusa con necrosis y hemorragias ${ }^{2}$. En Chile en el 2010, López O, describió un caso de meningoencefalitis chagásica en un paciente con infección por VIH/SIDA, con sobrevida a tres años ${ }^{3}$.

La asociación de enfermedad de Chagas y SIDA dio origen a cuadros poco frecuentes como peritonitis espontánea con numerosos tripomastigotes de Trypanosoma cruzi en líquido ascítico ${ }^{4}$, compromiso del pericardio y gastro-esofagomiositis ${ }^{5}$, diarrea crónica con identificación de amastigotes de $T$. cruzi en biopsias duodenales ${ }^{6}$, detección de amastigotes en piel $^{7}$ y en el cérvix uterino ${ }^{8}$. En la asociación de enfermedad de Chagas y SIDA, el SNC está afectado por el parásito en alrededor de 75\% de los casos, seguido por el sistema cardíaco en $\sim 44 \%$.

La reactivación de la enfermedad de Chagas también se observó en pacientes inmunocomprometidos con enfermedades malignas hematológicas, en pacientes sometidos a trasplantes de riñón o corazón y en pacientes con corticoterapia ${ }^{9}$.

En este informe se describe el caso de un paciente con SIDA y presencia de numerosos tripomastigotes de T. cruzi en el líquido pleural. Según nuestro conocimiento, este hecho constituiría el primer registro de la presencia de este parásito en el líquido pleural.

\section{Caso clínico}

Un paciente de sexo masculino, con 58 años de edad, oriundo de Santiago del Estero, Argentina, seropositivo para VIH sin cumplir con el tratamiento anti-retroviral, ingresó en agosto de 2010 al Hospital de Clínicas “José de San Martín” de la ciudad de Buenos Aires, con presencia de un síndrome constitucional. Meses antes, se le había diagnosticado neumonía por Pneu- mocystis jiroveci, comprobándose una pérdida de peso de $10 \mathrm{~kg}$ y cursaba con un recuento de linfocitos CD4 de 70 céls $/ \mathrm{mm}^{3}$.

En el examen físico se constató que el paciente estaba lúcido, padecía una cefalea de leve intensidad, holocraneana, sin foco neurológico alguno. En la palpación abdominal se evidenció un abdomen blando e indoloro y no se detectaron visceromegalias ni adenopatías. En la cavidad bucal se observaron lesiones blanquecinas en la lengua. El paciente estaba eupneico, con una buena entrada de aire bilateral y sin ruidos agregados. Presentaba ruidos cardíacos normofonéticos y silencios libres. La presión arterial era de 110/70 mm Hg, la frecuencia cardíaca 96 latidos por minuto, la frecuencia respiratoria $18 \mathrm{cpm}$, la temperatura corporal $37,2^{\circ} \mathrm{C}$, la saturación de oxígeno (con $\mathrm{FiO}_{2}$ 0,21): 96\%. Su peso corporal era $62 \mathrm{~kg}$, su altura 1,75 mts y el IMC 20.

En el laboratorio se constató la presencia de anemia ferropénica con plaquetopenia y un aumento marcado de LDH de 4.532 UI/L (VN: 480 $\mathrm{UI} / \mathrm{L}$ ). El recuento de linfocitos $\mathrm{CD}_{4}$ fue de 31 céls $/ \mathrm{mm}^{3}$. La serología para Chagas (IFI y hemoaglutinación) resultó no reactiva. Los estudios para virus de Epstein Barr (VEB) IgG (+) IgM (-), citomegalovirus (CMV) IgG (+) IgM (-) y Toxoplasma gondii IgG (+) IgM (-). La serología para hepatitis B y C fue Ag HBs (-) y anti VHC (-) respectivamente. El VDRL fue no reactivo.

La tomografía axial computada (TAC) de tórax y la imágenes radiográficas revelaron signos de enfisema centrolobulillar y dispersas opacidades peribronquiales, probablemente de origen inflamatorio, sin franca consolidación, de naturaleza inespecífica.

El electrocardiograma reveló la presencia de taquicardia sinusal, sin cambios en comparación con trazados previos.

En el examen directo de LCR no se observaban células, y el estudio físicoquímico arrojó los siguientes resultados: glucosa $50 \mathrm{mg} / \mathrm{dL}$ para una glicemia de $110 \mathrm{mg} / \mathrm{dL}$, cloro: 116 meq/L, proteínas: 34,5 mg \%. La prueba de tinta china para Cryptococcus spp resultó negativa.

El estudio del lavado bronco-alveolar reveló los siguientes datos: 130 céls $/ \mathrm{mm}^{3}$ con $82 \%$ de macrófagos alveolares, $16 \%$ de linfocitos y $2 \%$ de neutrófilos.

Los estudios baciloscópicos y los cultivos para microorganismos comunes resultaron negativos. La tinción de azul de toluidina o para $P$. jiroveci fue negativa. 


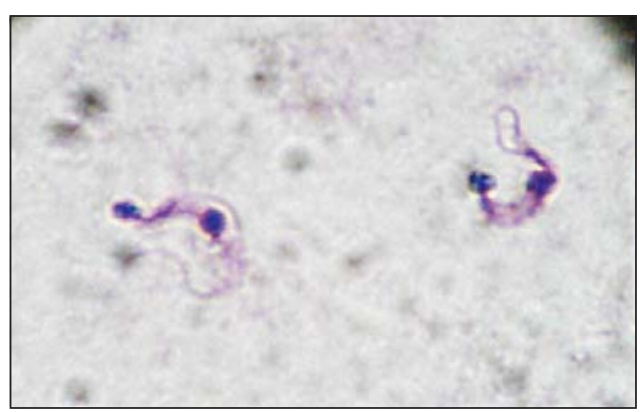

Figura 1. Tripomastigotes de Trypanosoma cruzi en líquido pleural con tinción de Giemsa $1.000 \mathrm{X}$.

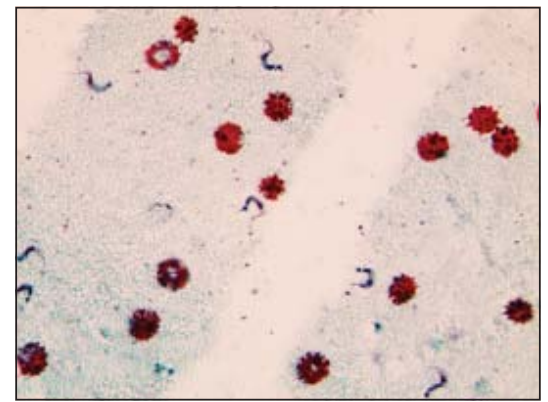

Figura 2. Tripomastigotes de Trypanosoma cruzi en líquido pleural con tinción de Papanicolaou $1.000 \mathrm{X}$.
En septiembre de 2010 presentó una neumonía intrahospitalaria de etiología desconocida, documentada mediante una radiografía de tórax. Los hemocultivos fueron negativos. Se inició antibioticoterapia con piperacilina/ tazobactam, vancomicina y polimixina.

La biopsia de médula ósea reveló un síndrome hemofagocítico secundario a VIH, CMV y VEB. La RPC cualitativa para CMV y VEB fue positiva. El paciente fue tratado con etopósido, dexametasona y foscarnet.

La biopsia cutánea de lesiones máculo-papulares rojo-vinosas reveló la presencia de sarcoma de Kaposi.

El paciente evolucionó con desviación del tabique nasal y una lesión necrótica en su interior. La TAC del macizo facial demostró la ausencia de cornete medio y una biopsia de la lesión permitió diagnosticar una mucormicosis que fue tratada con anfotericina liposomal y desbridamiento quirúrgico por vía endoscópica de las lesiones existentes en la cavidad nasal y los senos paranasales.

Debido a la presencia de efusión pleural se le practicó una toracocentesis obteniéndose líquido de aspecto límpido y color amarillo claro. El recuento celular fue de 70 céls $/ \mathrm{mm}^{3}$ (neutrófilos $42 \%$, linfocitos $55 \%$, monocitos 3\%) y muy escasos hematíes. El examen citológico reveló la presencia de tripomastigotes móviles de T. cruzi. Mediante la coloración de Giemsa y Papanicolaou se confirmó el diagnóstico (Figuras 1 y 2). El examen químico mostró: glucosa: $237 \mathrm{mg} / \mathrm{dl}$, proteínas 0,4 gr/l. El cultivo del líquido pleural fue negativo.

En el método directo de Strout se observó la presencia de abundante cantidad de tripomastigotes móviles. Al día siguiente el paciente falleció por paro cardio-respiratorio no traumático (noviembre de 2010).

\section{Discusión}

La presencia de tripomastigotes de T. cruzi en líquido pleural -según nuestro conocimiento-no ha sido descrita previamente en la literatura médica.

Este hallazgo probablemente se explique por la presencia de una efusión pleural y de esta manera se habría producido un pasaje de tripomastigotes al líquido. No consideramos que fuese una contaminación por una punción traumática debido a que el fluido obtenido era de aspecto límpido y de color amarillo claro.

La TAC de tórax y la imágenes radiográficas revelaron signos de enfisema centrolobulillar y dispersas opacidades peribronquiales, probablemente de origen inflamatorio, lo que descartaría un sarcoma de Kaposi de origen pulmonar.

La serología para enfermedad de Chagas no siempre es relevante para el diagnóstico en el caso de pacientes inmunocomprometidos ya que la inmunodepresión puede impedir la generación de una respuesta inmune ante una infección aguda (IgM) o bien, que la depresión inmunológica extrema podría negativizar serologías previamente positivas (IgG). En este informe, la serología para $T$. cruzi resultó negativa presuntamente como consecuencia de los bajos niveles de CD4.
Siempre es recomendable en pacientes con SIDA la búsqueda de este parásito en la sangre y en cualquier otro líquido de punción mediante la utilización de métodos directos, en forma especial en aquellos individuos provenientes de áreas endémicas de enfermedad de Chagas, con el propósito de evitar mayores riesgos en su salud.

\section{Resumen}

Se detectó la presencia de numerosos tripomastigotes de Trypanosoma cruzi en el líquido pleural de un paciente con SIDA proveniente de Santiago del Estero, Argentina. La enfermedad de Chagas es endémica en algunos países de América Latina. Según nuestro conocimiento el hallazgo de tripomastigotes de $T$. cruzi en el líquido pleural no ha sido previamente descrito en la literatura médica.

\section{Referencias}

1.- Del Castillo M, Mendoza G, Oviedo J, Pérez Blanco R P, Anselmo A E, Silva A M. AIDS and Chagas disease with central nervous system tumor-like lesion. Am J Med 1990; 88: 693-4.

2.- Rocha A, Oliveira de Meneses A C, Moreira da Silva A, Ferreira M S, Nishioka S A, Burgarelli M K N, et al. Pathology of patients with Chagas disease and acquired immunodeficiency syndrome. Am J Trop Med Hyg 1994; 50: 261-8.

3.- López M O. Meningoencefalitis chagásica en un paciente con infección por VIH/SIDA con sobrevida a tres años: Caso clínico. Rev Chil Infectol 2010; 27: 160-4.

4.- Iliovich E, López R, Kum M, Uzandizaga G. Peritonitis espontánea chagásica en un enfermo de SIDA. Medicina (Buenos Aires) 1998; 58: 507-8.

5.- Ferreira M S, Nishioka S de A, Silvestre M T A, Borges A S, Nunes Araujo F R, Rocha A, et al. Reactivation of Chagas disease in patients with AIDS: report of three new cases and review of the literature. Clin Infect Dis 1997; 25: $1397-400$.

6.- Corti M. Enfermedad de Chagas y síndrome de inmunodeficiencia adquirida. Enf Emerg 2003; 5: $13-7$.

7.- Sartori A M, Sotto M N, Braz L M, Oliveira Júnior Oda C, Patzina R A, Barone A A, et al. Reactivation of Chagas disease manifested by skin lesions in a patient with AIDS. Trans R Soc Trop Med Hyg 1999; 93: 631-2.

8.- Concetti H, Retegui M, Pérez G, Pérez H. Chagas’ disease of the cervix uteri in a patient with acquired immunodeficiency syndrome. Hum Pathol 2000; 31: 120-2.

9.- Cordova E, Boschi A, Ambrosioni J, Cudos C, Corti M. Reactivation of Chagas disease with central nervous system involvement in HIV-infected patients in Argentina, 1992-2007. Int J Infect Dis 2008; 12: 587-92. 